\title{
Geografía e historia en Iberoamérica: síntesis de su evolución y consideraciones contemporáneas
}

\author{
Miguel Enrique García Valladares \\ Instituto de Geografía \\ Universidad Nacional Autónoma de México \\ mikeegv87@gmail.com
}

Gustavo G. Garza Merodio y Gabriela Dalla Corte Caballero (coords.), Geografía e historia en Iberoamérica: síntesis de su evolución y consideraciones contemporáneas, Universidad Nacional Autónoma de México-Instituto de Geografía, 2015, 144 pp., ISBN: 978-607-027433-6.

La historia y la geografía son disciplinas que en la consideración general hacen buena mancuerna, pues los objetos de estudio de ambas son por demás próximos: la actividad del ser humano en el tiempo y el espacio. Pero en la práctica, habría que cuestionar ¿qué tanta cercanía hay o ha habido entre geógrafos e historiadores, si se supone que hay una afinidad?, ¿qué aspectos teórico-metodológicos habría que tomar en cuenta para que la interdisciplina sea efectiva?, ¿qué se está haciendo desde Iberoamérica? Esto es lo que, Gustavo Garza y Gabriela Dalla Corte, ${ }^{2}$ en coordinación con otros académicos, tratan de responder en Geografía e historia en Iberoamérica: síntesis de su evolución y consideraciones contemporáneas, publicado

${ }^{1}$ Estudiante de doctorado en geografía. Instituto de Geografía - Universidad Nacional Autónoma de México.

${ }^{2}$ Gabriela Dalla Corte, historiadora argentina, falleció el 24 de diciembre de 2017 en Barcelona.

c) (7) (9)

Esta obra está protegida bajo una Licencia Creative Commons Atribución-NoComercial 4.0 Internacional.

Secuencia. E-ISSN 2395-8464 http://secuen-

cia.mora.edu.mx/

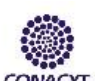

CONACYT

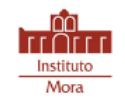


en 2015 por el Instituto de Geografía de la Universidad Nacional Autónoma de México, al reflexionar sobre las practicas geográfica e historiográfica iberoamericanas.

Desde el título, hay dos ideas que guían al lector en el cuestionamiento que se hace a la práctica contemporánea de la geografía histórica en Iberoamérica. Por una parte, en la utilización de Iberoamérica, se nota un posicionamiento que indica la consideración del contexto histórico y cultural -y no solo el origen geográfico-desde donde hablan los académicos de ambas disciplinas. En detrimento y claro cuestionamiento del uso de Latinoamérica o América Latina, que los coordinadores del libro consideran lejano e inexacto, a pesar de su amplio y mediático uso (p. 10).

Por otro lado, la obra parte de la idea que el ejercicio interdisciplinario de la geografía histórica se realiza desde el lugar ideológico y temporal de quien escribe y, en consecuencia, es necesario ponderar lo que se ha investigado. En otras palabras, la apuesta de este libro es hacia una historiografía de la geografía histórica, que invite a repensar su escritura, su posición como rama de la geografía y "desde parcelas socioeconómicas y culturales ajenas a los centros hegemónicos de poder intelectual y tecnológico”, es decir, desde el contexto iberoamericano actual (p. 13).

En esa forma, el libro se divide en tres partes. La primera está pensada como un puente entre la geografía y la historia, de parte de los coordinadores Gustavo Garza Merodio y Gabriela Dalla Corte Caballero. La segunda ofrece dos propuestas metodológicas para la geografía histórica, desde el giro cultural; mientras que la tercera lo hace junto a la geografía cultural.

El puente de ida y vuelta que el geógrafo mexicano y la historiadora argentina desarrollan en la primera parte analiza el estado de la relación existente entre los académicos de cada área y la otra disciplina, a partir de la producción historiográfica interdisciplinaria. Es decir, los geógrafos en relación con la historia y los historiadores respecto a la geografía.

En la primera dirección, Gustavo Garza hace una crítica hacia la práctica interdisciplinaria. Reconoce la importancia de los giros cultural en geografía y el espacial en las ciencias sociales; las contribuciones teóricas de Milton Santos y Antonio Moraes, quienes han invitado

Secuencia. E-ISSN 2395-8464 http://secuencia.mora.edu.mx/ 
a reflexionar sobre el papel de la historia en los estudios geográficos en general; además de la importancia del concepto altepetl para las historiografías prehispánica y virreinal en México.

No obstante, para Garza, aun permea cierto positivismo entre las academias de geografía, especialmente en Brasil, Argentina y México. Un positivismo que se ha traducido muchas veces, en la constante división entre una geografía física ateórica, y una geografía humana desconfiada de la historia y los historiadores. Esto último, pese a la importancia de la geopolítica y la geohistoria, como conceptos clave en la relación entre ambas disciplinas.

En la dirección contraria del puente, Gabriella Dalla Corte también cuestiona el vínculo entre historiadores y geografía. A pesar de que la idea de la historia patria tenía un componente espacial, el positivismo decimonónico relegó a la geografía como el marco de ubicación de las historias nacionales en Iberoamérica. Análogamente, en el siglo XX, el concepto de región no ayudó mucho al acercamiento de los historiadores con la geografía, pues en vez de analizar la región como una categoría espacial en los estudios históricos, mantuvo su carga posibilista y, en términos políticos, se confundió con la escritura de historias de las provincias, departamentos o estados de cada país, en favor de los centros de poder.

Asimismo, la historiadora argentina reconoce que las corrientes historiográficas de la segunda mitad del siglo XX han ayudado a proponer nuevos esquemas teórico-metodológicos. De hecho, aun cuando se trata de perspectivas surgidas en Europa, los historiadores iberoamericanos han adoptado esas propuestas para cuestionar las periodizaciones de las historias nacionales, el papel de los pueblos indígenas y el lugar de Iberoamérica en el mundo. Cuestiones en las que la consideración del espacio en la historia ya no es un asunto menor.

En esta primera parte, ambos colegas hacen una crítica oportuna al estado de las relaciones entre académicos de ambas disciplinas. A pesar de los elogios a la existencia de líneas de investigación interdisciplinarias, aún falta mucho para superar los esquemas positivistas y autorreferenciales en historia y geografía. Esquemas que desembocan en actitudes de acercamiento «más por afanes intelectuales, que por un deseo consciente de interactuar» con otros colegas (p. 22). Por ello resulta acertado que esta primera parte se plantee como una revisión

Secuencia. E-ISSN 2395-8464 http://secuencia.mora.edu.mx/ 
de ida y venida, cómo ven los geógrafos a los historiadores y viceversa, a través de sus trabajos, a fin de actuar para que el intercambio de ideas sea realmente efectivo.

La importancia del giro cultural en geografía y su vínculo con la historia es abordado en la segunda parte. El geógrafo Federico Fernández Christlieb se vale del padre común a la geografía y la historia: Heródoto de Halicarnaso, para hablar del paisaje como texto histórico. Es interesante el recurso al explorador griego, ya que Fernández Christlieb analiza la metodología de investigación utilizada para la escritura de sus Historias (p. 59). Dicha metodología que se resume en la aplicación de las habilidades más básicas para la reconstrucción de geografías pretéritas: la observación, la escucha de los informantes actuales y la valoración de las fuentes.

Por su parte, Raquel Urroz analiza la percepción europea de todo un continente desconocido hasta el siglo XVI, a partir de la cartografía desarrollada en ese tiempo. La historiadora explica cómo el proceso de destrucción y conquista de América produjo realmente un nuevo mundo que, sin embargo, tomaría en cuenta las realidades americanas previas: la mesoamericana centrada en Tenochtitlan y la andina en Cuzco, de donde surgirían los virreinatos de Nueva España y Perú, respectivamente. Si bien culturas paganas, ambas reconocidas como principales focos de lo que los europeos veían como civilidad, en oposición a la Gran Chichimeca norteamericana y el Collasuyu sudamericano.

En esa forma, Urroz Kanán se vale de la producción cartográfica del siglo XVI para una lectura de la percepción que los europeos formaban como consecuencia de los descubrimientos geográficos. Todo ello, como parte de la reconfiguración geográfico-cultural de todo un continente, que, desde luego, no quedó en intercambios culturales, la construcción de ciudades y la evangelización, sino en la destrucción de culturas y el desplazamiento de pueblos vistos como salvajes.

Los artículos intermedios del libro son interesantes en la propuesta para repensar los ejercicios interdisciplinarios, a partir de Heródoto y la cartografía de América en el siglo XVI. Esto, a pesar de los obstáculos que en términos metodológicos puedan existir entre geógrafos e historiadores; el que, para los primeros, la particularidad de la escritura de los resultados de

Secuencia. E-ISSN 2395-8464 http://secuencia.mora.edu.mx/
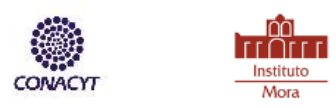
investigación está en las imágenes y en los segundos en la narrativa (Mendoza Vargas y Busto Ibarra, 2010, p. 136).

Desde otra perspectiva, Gustavo Garza habla sobre el «siglo de las conquistas» en el penúltimo capítulo, en la tercera parte del libro. Desde una reflexión de las posibilidades teórico-metodológicas que ese periodo ofrece para la geografía histórica y la geografía cultural, Garza Merodio toma como punto de partida las urbes hispanas y los pueblos de indios americanos surgidos tras la irrupción europea, para proponer «una geografía histórica que se fundamente en el análisis de discursos y manifestaciones culturales de comunidades y colectivos» (p. 96).

Al igual que Raquel Urroz, el geógrafo señala la importancia de los centros mexica e incaico como plataformas para la reconfiguración de los procesos espaciales americanos. Pero a diferencia de ella, la propuesta de Garza Merodio consiste en la deconstrucción de esos procesos, a partir del giro lingüístico o cultural en geografía. Este enfoque lleva a cuestionar la explicación en la que los americanos fueron pasivos ante la irrupción europea y la imposición de sus instituciones, ya que subraya el papel de las entidades político-territoriales -el altépetl mesoamericano y la saya andina-, y del idioma -náhuatl y quechua como lenguas francas-, en la transformación y construcción de los nuevos paisajes iberoamericanos, junto a sus sociedades (p. 103). Paisajes que cambiaron no por la sustitución de pirámides por iglesias, sino por la adaptación de los sistemas espaciales europeos a las realidades americanas -como las congregaciones-, lo que traería evidentes consecuencias para los procesos geohistóricos de los siglos posteriores.

El último capítulo fue escrito por José Omar Peral Garibay como una propuesta de geografía cultural, a partir del caso de la ciudad de Oaxaca. El geógrafo explica cómo la misma historia de esta urbe la han dotado de un capital cultural que ha sido explotado en décadas recientes, gracias a la adquisición del título de Ciudad Patrimonio de la humanidad en 1987. Pero entre los reconocimientos y la acumulación de ese capital cultural, existe toda una construcción histórica del espacio que ha correspondido a los propios habitantes de la «Ciudad esmeralda». Situación que se enfrenta a la explotación capitalista del patrimonio urbano, a

Secuencia. E-ISSN 2395-8464 http://secuencia.mora.edu.mx/
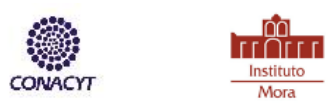
través del turismo, como en la controversia por la instalación de un restaurante McDonald's en el centro de la ciudad (pp. 123-124).

Esta tercera parte expone ya un par de propuestas temáticas sobre el análisis de la relación sociedad-naturaleza en el tiempo. El texto de Garza Merodio es una reflexión metodológica acerca de cómo se pueden entender los procesos históricos del siglo XVI, desde la geografía, aprovechando los aportes de historia, antropología y etnohistoria. Por su parte, Peral Garibay hace una reflexión menos interdisciplinaria, pero no por ello menos interesante. Su texto llama al debate público sobre el uso y explotación de los patrimonios histórico-culturales, lo que por extensión invita a cuestionar la implantación de proyectos turísticos como los «pueblos mágicos» o la apropiación comercial del Día de Muertos.

Por todo lo anterior, Geografía e historia en Iberoamérica: síntesis de su evolución y consideraciones contemporáneas es un libro pequeño, pero ambicioso, que constituye una contribución valiosa para el diálogo entre geógrafos e historiadores. No obstante, habría sido interesante abarcar la reflexión historiográfica en geografía histórica con ejemplos de otros periodos iberoamericanos y no solo el siglo XVI; o bien, que hubiese participación de colegas de otras latitudes (además de Gabriela Dalla Corte), en lugar de tratar el subcontinente desde México. Aunque tales situaciones habrían sido más difíciles materialmente, lo que dice mucho de aquellas barreras que tienen más que ver con la política e instituciones académicas, que con la voluntad de diálogo entre investigadores de temáticas afines.

\section{Referencia}

Mendoza Vargas, H., y Busto Ibarra, K. (2010). La Geografía histórica de México, 1950-2000. En Construyendo la Geografía Humana. El estado de la cuestión desde México (pp. 132-151). México: Universidad Autónoma Metropolitana- Iztapalapa.

Secuencia. E-ISSN

2395-8464 http://secuencia.mora.edu.mx/ 